\title{
A critical analysis of purchasing arrangements in Kenya: the case of micro health insurance
}

\author{
Kenneth Munge ${ }^{1 *}$ D, Stephen Mulupi ${ }^{1}$, Edwine Barasa ${ }^{2}$ and Jane Chuma ${ }^{1,3}$
}

\begin{abstract}
Background: Strategic purchasing can ensure that financial resources are used in a way that optimally enhances the attainment of health system goals. A number of low- and middle-income countries, including Kenya, have experimented with micro health insurance (MHIs) as a means to purchase health services for the informal sector. This study aimed to examine the purchasing practices of MHIs in Kenya.
\end{abstract}

Methods: The study was guided by an analytical framework that compared purchasing practices of MHIs with the ideal actions for strategic purchasing along three pairs of principal-agent relationships (government-purchaser, purchaser-provider and citizen-purchaser). The study adopted a qualitative descriptive case study design with 2 MHIs as cases. Data were collected through document reviews (regulation, marketing materials, websites) and semistructured interviews with key informants $(n=27)$.

Results: The regulatory framework for MHIs did not adequately support strategic purchasing practice and was exacerbated by poor coordination between health and financial sectors. The MHIs strategically contracted health providers over whom they could exercise bargaining power, sometimes at the expense of quality. There were no clear channels for beneficiaries to provide timely feedback to the purchaser. MHls premium payments were familybased, low-cost and offered limited benefits. Coverage was based on ability to pay, which may have excluded lowincome households from membership.

Conclusions: Adequate policy, legal and regulatory frameworks that integrate MHIs into the broader health financing system and support strategic purchasing practices are required. The state departments responsible for finance and health should form coordinating structures that ensure that MHI's role in universal health coverage is owned across all relevant sectors, and that actors, such as regulators, perform in a coordinated manner. The frameworks should also seek to align purchasers' relationships with providers so that clear and consistent signals are received by providers from all purchasing mechanisms present within the health system.

Keywords: Micro Insurance, Micro health Insurance (MHI), Strategic purchasing, Low- and middle-income countries (LMIC), Health financing, Universal health coverage

\footnotetext{
* Correspondence: kmunge@kemri-wellcome.org

${ }^{1}$ Institution: Health Economics Research Unit, KEMRI Wellcome Trust Research

Programme, PO Box 43640 00100, Nairobi, Kenya

Full list of author information is available at the end of the article
}

(c) The Author(s). 2019 Open Access This article is distributed under the terms of the Creative Commons Attribution 4.0 International License (http://creativecommons.org/licenses/by/4.0/), which permits unrestricted use, distribution, and reproduction in any medium, provided you give appropriate credit to the original author(s) and the source, provide a link to the Creative Commons license, and indicate if changes were made. The Creative Commons Public Domain Dedication waiver (http://creativecommons.org/publicdomain/zero/1.0/) applies to the data made available in this article, unless otherwise stated. 


\section{Background}

Universal health coverage (UHC) is a global agenda with particular relevance for low- and middle-income countries (LMICs), whose populations face challenges in access to services of sufficient quality when needed, and remain at risk of health related impoverishment [1]. For countries to make progress to UHC, it is important that their health financing systems promote UHC goals: revenue generation mechanisms to which contributions are fair and offer financial risk protection [2]; pooling arrangements that reduce fragmentation and allow for effective income and risk cross subsidization to ensure equity and sustainability [3]; and purchasing arrangements that actively pursue the best possible ways to optimize quality, efficiency, equity and responsiveness of health service provision [4].

Purchasing involves determining what to buy (benefit package), for whom (target beneficiaries), from whom (healthcare providers) and for what price [4]. Purchasing can be passive or active also known as strategic purchasing [1]. The former implies a reliance on historical patterns of priority setting, resource allocation and financial management while strategic purchasing involves seeking the optimal way to organize these activities with the aim of reaching health system goals [5]. Strategic purchasing, therefore, involves performing the purchasing activities in a way that continuously seeks to promote quality, efficiency, equity and responsiveness of the health system $[4,5]$. Strategic purchasing is critical for the attainment of UHC [6], and is arguably even more important for micro insurance, which targets low-income earners, who often have higher need for health services.

Micro insurance refers to insurance services targeting principally low-income earners, who are excluded from mainstream commercial and social insurance schemes, due to affordability barriers [7-11]. Generally, micro insurers provide a limited set of benefits to members at low premiums, making them affordable to low-income households.

Micro health insurance (MHI and also referred to as HMI) refers to the provision of health insurance services to these households in exchange for premiums charged on the basis of the risk involved $[8,12]$. MHI can improve access to health services, offer financial risk protection through reduction in out of pocket expenditures [12]. It has been shown that MHIs, and micro insurance firms in general, tend to have small risk pools and face difficulties in generating sufficient resources [7] which can impact their ability to act as strategic purchasers. More specific evidence on purchasing arrangements suggests that $\mathrm{MHI}$ face challenges in designing benefit packages that remain affordable while offering sufficient coverage, obtaining health service providers who offer quality and efficiency, and managing claims in an administratively efficient way [12].
Some LMICs have experimented with micro health insurance (MHIs) to purchase health services [7, 13]. It is thought that in these settings MHI can expand social protection mechanisms; reach groups usually excluded from health insurance such as the informal sector; address gender-inequalities in access to insurance; be designed to better suit customer preferences; and offer better accountability arrangements for financial and service delivery performance [8]. The limited empirical evidence shows that strategic purchasing practice is not widespread among MHI [14-17]. The key aspect of strategic purchasing employed was determining who to buy from with evidence of selection and contracting based on capacity, quality and cost considerations $[13,15,17]$. Other activities identified were benefit package design, where the trade-off between affordability and comprehensiveness was identified; and the use of provider payment mechanisms with fee for service and budgets being the most widely used forms $[13,15,17]$.

\section{Health micro insurance in Kenya}

As with other LMICs, Kenya's pursuit of UHC has gained momentum and several reforms have been implemented. These include the removal of user fees in government-owned dispensaries and health centres and the introduction of free maternity services in public facilities [18, 19]. Other reforms have targeted the National Hospital Insurance Fund (NHIF), Kenya's social health insurance scheme, and include expansion of the benefit package to include outpatient and specialized services such as renal dialysis, an increase in contribution rates, and governance restructuring [20-22]. Despite these efforts, only $17 \%$ of Kenyans had any form of health insurance in 2013 [23], and this number is unlikely to have increased significantly in the recent past. Health insurance coverage remains low especially among the poor and low-income households who mainly work in the informal sector, which makes up $83 \%$ of Kenya's labour force [23-26]. For example, provisional estimates from 2015 show that only 16\% of all informal sector workers in Kenya have NHIF insurance [27]. The low levels of insurance coverage present a challenge for Kenya at a time when mandatory health insurance is being considered as a main financing mechanism for UHC [28-30]. Micro insurance is expected to play a role in the country's progress towards UHC and broader social protection $[28,31]$.

Micro-insurance schemes are categorized in several models: partner-agent, provider-driven, mutual model (community-based) and the direct agent model [7, 8, 32]. In the partner-agent model, an insurance firm contracts another entity to sell it products, while under direct agent model, an insurance firm controls the entire chain and sells its product directly to consumers [8]. 
The mutual or community-based model is owned and run by scheme members through participatory mechanisms [7, 8 , 33]. The provider driven model is led by a health service provider who takes on an insurance function [7]. All four models of micro insurance are present in the Kenyan health insurance context. The provider-driven model and the community-based model are frequently lumped together and referred to as community-based health insurance (CBHI) schemes [34]. These two models lack a legal and policy framework and tend to be administered as societies or community-based organisations [33, 35]. On the other hand, the partner-agent and direct agent models are labelled as MHIs and have received increasing policy and regulatory attention from the Kenyan government $[31,36]$.

There are other features that distinguish CBHI and MHIs in Kenya. CBHI operate within a specific small geographical location [33, 37], while MHIs operate nationally [38]. Access to services for CBHI members is usually restricted to low-cost public facilities and faith based facilities within the same geographical area, while MHIs have a nationwide network of low- to mid-cost public and private providers [35]. Additionally, while MHIs offer risk rated premiums to members calculated individually or for groups, CBHI schemes base premiums on members' decisions, informed by very limited financial analysis, if any [33].

There is no accurate data on the number of and population covered by MHIs in Kenya, largely due to weak regulation, and existing reporting requirements where their activities are recorded under the insurance firms that underwrite the products $[31,38]$. A report published in early 2014 suggested that about 300,000 lives were covered: about $1 \%$ of Kenya's population [39].

There is growing interest in Kenya and globally on the role of MHIs as a mechanism for health financing towards UHC [7]. MHI are not only of interest to health policy makers, but also to those from the finance and social sectors who may be interested in the financial and social inclusion potential of MHI [8, 40]. This concern has not been matched with a systematic examination of whether these purchasing practice of MHI are strategic. This paper addresses this evidence gap by examining purchasing practices of MHIs and the extent to which these are aligned to strategic purchasing.

\section{Methods}

\section{Study setting}

Kenya's health system is organized around two major administrative levels: the national, that is primarily responsible for policy, regulation and national referral facilities; and the county level that is largely responsible for service delivery. Health care services are provided by both private (for-profit and not-for-profit) and public providers in almost equal shares [41]. Health care services, especially in the public sector, are arranged in tiers from community through to tertiary care [42]. Health is financed by the government (31\% of total health expenditure, THE), private sources (mainly through out of pocket payments which are $32 \%$ of THE) and donors (25\% of THE) [43]. The majority of Kenya's insured population (88\%) are covered by the NHIF [23]. The rest are covered by private health insurance which includes MHIs (9\%), employer-based medical schemes (about 3\%) and CBHIs $(<1 \%)$ [23]. At the time of this study, there were 18 private health insurers and 29 medical insurance providers in Kenya; the latter being a special class of health insurance providers who do not underwrite their own products $[36,44]$.

\section{Study design and data collection}

The study adopted a qualitative descriptive case study design. Two MHIs were purposively selected as case studies based on discussions with policy makers. The first organization (MHI Case A) was a mobile phone innovation focussed firm, which had partnered with a telecommunications company and an insurance underwriter to develop and market a health micro insurance product. The second (MHI Case B) was a leading micro finance institution that had partnered with the same insurance underwriter. The insurance underwriter (Private Insurance Firm C) was one of the largest insurance firms in Kenya and also provided micro health insurance under a direct agent model. Though both were partner-agent models, there was the view that they would provide sufficient data to meet the objective of the study and that any gaps would then be filled by the experiences of Private Insurance Firm $C$. The characteristics of the cases are summarized in Table 1:

Data were collected between April 2014 and May 2015, through document review and semi-structured interviews with key informants. Documents reviewed included statutes, reports, policy documents, websites content and grey literature. Specific to the two MHIs, we reviewed websites, sales material documenting their benefit packages, and project evaluation reports. Documents were retrieved by the authors independently and also obtained from respondents. Data were extracted into standardised forms and a summary assessment of the reviewed documents was produced. Semi-structured interviews were conducted with micro health insurance providers ( 1 from Case A and 1 from Case B), micro health insurance underwriters (1 underwriting both Case $\mathrm{A}$ and $\mathrm{B}$, and 2 underwriting other $\mathrm{MHI}$ ) and regulators ( 2 regulating both Case $\mathrm{A}$ and $\mathrm{B})$. Additional interviews were conducted with independent actuaries $(n=2)$, other private health insurance players $(n=8)$, industry lobby groups $(n=1)$ and health service providers $(n=9)$. Table 2 presents a summary of the respondents. 
Table 1 Summary of Case Study Micro Health Insurance Firms

\begin{tabular}{|c|c|c|}
\hline & MHI Case A & MHI Case B \\
\hline Model & Partner-agent model & Partner-agent model \\
\hline Underwriter & & Private Insurance Firm C \\
\hline Area of operation & National & National \\
\hline Benefit package $[45,46]$ & $\begin{array}{l}\text { Outpatient and inpatient services Family-based cover } \\
\text { Other benefits: } \\
\text { Daily hospital cash, Funeral benefit, Cover limit } \\
\text { in two bands KES 139,000 and KES 290,000 } \\
\text { No premium financing }\end{array}$ & $\begin{array}{l}\text { Outpatient and inpatient services Family-based cover } \\
\text { Other benefits: } \\
\text { Life insurance cover, Funeral benefit, Cover limits } \\
\text { in three bands KES 200,000, KES 500,000 and KES } \\
1,000,000 \\
\text { Premium-financing available through } \\
\text { micro-finance loan }\end{array}$ \\
\hline Premium rate $[45,46]$ & KES 12,000 for full benefit & Not determined \\
\hline Number of members & About 8000 in late $2014^{\mathrm{a}}[46]$ & About 12,000 in 2014 [39] \\
\hline Health service providers & Public and low- and mid-cost private health facilities & Public and low- and mid-cost private health facilities \\
\hline
\end{tabular}

as many as 65,000 at fold up in 2015 [47]

Respondents were approached through phone and email, informed of the general objectives of the study and requested to participate in an interview. Semi-structured interviews were conducted face-to-face at the respondents' place of work. Written informed consent was sought before the commencement of each interview. Interview questions were based on the conceptual framework (Table 3 ). Interviews took about $1 \mathrm{~h}$ and were audio recorded, with field notes taken by the accompanying researcher who also sought clarification on key points during the interview.

\section{Conceptual framework}

The study was guided by an analytical framework summarized in Table 3. The purchasing practices of MHIs were compared with the ideal actions for strategic purchasing along three pairs of principal-agent relationships (government-purchaser, purchaser-provider and citizenpurchaser) proposed by the Responsive and Resilient Health Systems (RESYST) Consortium [48]. Drawing on agency theory and guided by Figueras et al's framework [4], the RESYST framework specifies actions that the purchaser can take to ensure that the agent acts in a

Table 2 Summary of respondents

\begin{tabular}{|c|c|c|c|}
\hline \multirow[b]{2}{*}{ Respondent } & \multicolumn{3}{|c|}{ Number interviewed } \\
\hline & MHI Case A & MHI Case B & Other \\
\hline MHI providers & 1 & 1 & \\
\hline $\mathrm{MHI}$ underwriters & 1 & & 2 \\
\hline Insurance regulators & & & 2 \\
\hline Health Service Providers & & & 9 \\
\hline Other private insurance firms & & & 8 \\
\hline $\begin{array}{l}\text { Independent actuaries } \\
\text { and consultants }\end{array}$ & & & 2 \\
\hline $\begin{array}{l}\text { Insurance industry association/lobby } \\
\text { group }\end{array}$ & & & 1 \\
\hline
\end{tabular}

way that benefits the principal. The description of ideal actions is based on reviews of the existing literature on strategic purchasing and the experiences of the reviewers and consortium members who are experts in health financing. For this study, the government-purchaser axis was approached from an industry-wide perspective, with the government including the national government and insurance industry regulators in charge of the micro insurance sector as a whole. The purchaser-provider and provider-citizen axes were approached from a scheme specific perspective using the two MHIs as cases.

\section{Data analysis}

The audio recordings were transferred onto a secure computer, assigned a unique code and transcribed verbatim before being checked for consistency and correctness. Checked transcripts were then transferred into QSR NVivo 10 for coding and analysis. Coding was performed using thematic framework analysis with themes drawn from the analytical framework. Two researchers (KM and SM) coded the transcripts separately. Contentious coding outputs were agreed through consensus with a senior researcher (EB and JC). A feedback meeting was held with respondents to obtain their views of the study results. Other means of ensuring rigor of the study included the triangulation of interview data with data drawn from documents, and the utilisation of more than one organization to provide as wide a range of data as possible.

\section{Results}

\section{Government-purchaser relationship Inadequate regulatory framework}

Kenya lacks a specific health insurance law and regulatory framework. Health insurance is governed by the Insurance Act [36], and registration is done through the Insurance Regulation Authority (IRA). However, the 
Table 3 Strategic Purchasing actions

\author{
Government-Purchaser axis \\ Governments should provide policy and regulatory frameworks \\ that support strategic purchasing \\ Purchaser-Provider axis \\ Purchasers should select and contract health service providers \\ based on criteria including capacity and geographical distribution \\ Purchasers should require providers to ensure quality of service \\ including through quality improvement mechanisms such as \\ the use of standard treatment guidelines \\ Purchasers should incentivize provider performance through \\ payment mechanisms and related incentives \\ Citizen-Purchaser axis \\ Benefit packages should reflect needs and preferences of the \\ target population \\ Benefit packages should offer protection from financial catastrophe
}

Source: Adapted from RESYST [48]

Insurance Act does not cover key aspects of health insurance and the IRA lacks adequate capacity to handle aspects related to health insurance. Specifically, there are no guidelines on contribution rates and corresponding or minimum benefit package, nor are there any general indications for selecting providers. This inadequacy extends to micro insurance with few health-specific provisions in insurance policy and regulatory frameworks. For example, the Micro Insurance Policy Paper proposes that waiting periods for maternity, surgical and other benefits be 9 months, 6 months and 2 months respectively [31]. These proposals are not reflected in existing insurance law or in draft regulations and there are currently no guidelines supporting their implementation $[36,49]$. They are also not linked to any particular health policy or regulation and may therefore not address health goals of increasing access to care [50].

\section{Purchaser-provider relationship Strategic provider selection}

The MHIs preferentially contracted low- and mid-tier cost public and private health providers over whom they could exercise bargaining power by offering their client base to them. Neither of the MHIs was involved in the selection and contracting process; they instead leveraged on the experience and capacity of the underwriter, Firm C. Nevertheless, the MHIs communicated client preferences for health service providers to Firm C.

"So whenever we are contracting you the first thing we want to know [is] these kind of services how much do you charge...so if the answer is that it's more than $X$ which is our average, we don't want to work with you. If your answer is $X$ and below then, we're happy to work with you simple." PHI_10

\section{Weak quality assurance}

Focusing on cost of care sometimes undermined quality of services. The challenge to attaining good quality of services was clear to the MHIs manifested for example as long waiting times.

"The challenge is there is always the view that...these people will not pay immediately especially if there are those who are paying cash. And they will not...get... fast service because maybe when you come with the card, there is a process you must follow..." PHI_10

In order to address quality assurance, the MHIs piggybacked on measures undertaken by Firm $\mathrm{C}$ where these existed. From document review and interviews, these included accreditation, regular inspection and customer satisfaction reviews. However, these measures were variably applied owing to a lack of capacity and a poorly applied overarching quality framework for the health sector. Key quality improvement levers such as clinical guidance and support mechanisms or monitoring and performance measurement were not in use or were left to providers' professional judgement and discretion.

Beneficiaries who experienced poor quality services were unable to present timely feedback owing to a lack of clear communication channels between themselves and the purchaser. This was contributed to in part by the existence of multiple intermediaries in the chain between the beneficiary and the purchaser. For example, in Case B had developed a call centre that filtered calls before onward submission to the insurance underwriter, Firm C. However, Case B had no means of ensuring quality issues were taken care of, as this was legally the responsibility of the underwriter.

"Well because we have this call centre we are then able to prioritize...then decide who is responsible and [Private Insurance Firm C] have a team that actually engages with providers or customer complaints." PHI_01

\section{Weak incentives for provider performance}

The provider payment mechanism utilised by both MHIs was fee-for-service, linked to their use of the same insurance underwriter. In keeping with theory and evidence, there was the perception that this might have resulted in overuse and fraud.

"... by and large if you look at the health insurance particularly from the outpatient point of view, the abuses and the fraud that underlies it is enormous." KII_18_industry association 
Providers resisted movement to new forms of provider payment because of concerns over the way in which rates were estimated, and providers had power over purchasers. This power was drawn in part from their limited supply and their control over key rate setting mechanisms [51].

"So, the resistance simply comes as, 'We don't want to take capitation and we know you are still going to use our services.' If they knew that they will miss out on the business, if they didn't take capitation then the behavior of many of these providers will change..." PHI 06

"Capitation has been attempted a few times...but it has really not picked up properly...there is need for a proper actuarial study to be commissioned where there is no vested interest, because a lot of times somebody say we are doing an actuarial study but they have got vested interests, so the result is already skewed to favour what you want to come out of it." KII_23_provider

\section{Purchaser - Citizen relationship \\ Coverage based on ability to pay}

MHIs premium payments were family-based and could be characterized as "low-cost, low-cover". However, coverage and therefore access to services was based on ability to pay. For example, Case A offered three levels of financial limits depending on the premium paid. Similarly, Case B offered restricted access to benefits to those who paid half of the annual per household premium (KES 6000; USD 60) and full access to those paid the annual premium (KES 12,000; USD 120).

This may have restricted access to the poor and informal sector, which is characterized by low and irregular income. Case A addressed this problem by offering loans through its microfinance platform to finance premiums.

"The option of loan... we let them be in groups where they can guarantee one another and repay every week a small premium to cater for their medical; so that we pay full premium for them and then they slowly by slowly repay the loan" PHI_11

Case B encouraged users to save up to the premium and used its partnership with a telecommunications company to encourage mobile-based payments. However, the effectiveness of these solutions is questionable given the low uptake of products offered by both MHIs. For example, Case B has since withdrawn its product and private insurance Firm $\mathrm{C}$ now only offers products that charge higher premium rates that are restricted to groups of minimum 10 members.

\section{Inadequate financial risk protection}

Another barrier to financial risk protection was the absence of caps on balance billing, which meant that providers could charge users directly for costs that exceeded their cover limit. These top-up payments would therefore need to be made out-of-pocket exposing households to financial catastrophe. However, this was mitigated somewhat by the deliberate contracting of low- and middle-cost health service providers, and with integrating the packages with NHIF cover, which covered some of the cost of care.

"When you design a product, a key component into the product benefits and the pricing, will be the type of provider you use. For a faith-based hospital or a commercial high-end hospital the pricing will be different." PHI_04

\section{Needs-based benefit package design}

MHIs partnered with the insurance underwriter to assess health needs through market analysis, customer surveys and feedback, mystery shopping and intelligence gathering from competitors. For example, Case A used internal intelligence gathered as a microfinance institution to influence product design and distribution. Their data suggested that potential users preferred easy to understand products as well as continuous engagement. As a result, both MHIs benefit packages were simple, provided unique features such as funeral expense benefit, and had innovative options for premium payments, for example, through the use of mobile phones. Waiting periods for services, such as maternity services, were shorter than conventional insurance.

"When the customer comes in for a loan, we also tell him 'You see we have another product here which will be able to assist your family." PHI_11

These needs assessment activities also served the insurer well by reducing complaints and improving the chances for dispute resolution.

"When people know what they're buying, they will not complain because our message always is... 'We want to tell you what we're selling to you'..." PHI_10

However, benefit packages still excluded important preventive health services such as immunizations and vaccines, annual health checks, and family planning. 
Moreover, the use of evidence did not extend to more robust sources with cost cited as an impediment.

\section{"...Research is a very expensive venture, we try to do as often as we can but of course because of the cost again it's not possible." PHI_10}

\section{Discussion}

We have presented here how health micro insurance in Kenya functions in terms of strategic purchasing practice. The shortcomings are identifiable in each of the four decisions purchasers must make, i.e. what to buy, for whom, from whom and how.

Overall, the shortcomings in the four decision making domains were due to an inadequate policy and regulatory framework for strategic purchasing. This concern is echoed by previous work in Kenya and other LMIC [35, 52-54]. This is a more significant problem for MHIs, which operate under a variety of labels, mandates, motivations and even sectoral contexts. In the case of Kenya, the recent micro insurance policy [31] and amendments to the Insurance Act [36] represent missed opportunities for embedding strategic purchasing practice in a nascent form of insurance. This may be attributed to lack of stewardship by the government and limited stakeholder engagement [55]. In addition, the Insurance Regulatory Authority (IRA), under whose remit MHIs and insurance regulation fall, is answerable to the Ministry of Finance, with limited engagement, if any of the Ministry of Health $(\mathrm{MOH})$. This arrangement potentially contributed to weak policy coordination between the IRA and the $\mathrm{MOH}$. The intersection of financial and health sectors presents an opportunity for collaboration and coordination that would allow MHIs to contribute to health financing arrangements [56].

The inadequacy of policy and regulatory frameworks may result in unintended outcomes. For example, we identified the use of loans for premium financing through microfinance mechanisms. While this may be viewed as a means of addressing affordability and access to the package of health services, there is evidence that microfinance loans can have adverse effects if poorly implemented. In particular, evidence from India highlights that poorly designed and implemented microfinance solutions can contribute to financial strain in households $[57,58]$. Though these experiences have not been documented in Kenya, they provide relevant policy lessons related to premium rates, a concern relevant to strategic purchasing. Where premium rates increase over time they may exert increasing pressure on households.

In the absence of overarching guidance on what to buy and for whom, MHIs showed some ability to reflect member needs and preferences in the design of benefit packages, based on feedback from providers and beneficiaries (informal sector workers and other low-income earners). However, the extent to which this information was used to revise the benefit package was limited to keeping the package succinct and simple. There was little use of robust sources of evidence to inform service entitlements with the result that some cost-effective services were excluded from benefit packages. In addition, the focus on curative care failed to address the changing pattern of disease in Kenya, which may require a greater focus on health promotion and prevention. For example, non-communicable diseases, which are potentially preventable and require health promotion, contributed 30\% (95\% CI 26.4-33.3) of the total DALYs and 27\% (23.4-31.5) of all deaths in Kenya in 2016 [59]. A review of CBHI benefit packages offered in sub-Saharan Africa in 2011 revealed that most offered limited benefits with high co-payments [13].

Provider selection, based on capacity to deliver services and to expand geographical access, is essential to ensuring that beneficiaries can access their entitlements [4]. MHIs demonstrated strengths in selecting providers who fulfilled these requirements. However, shortages in supply of health services can reverse the power relationship between purchasers and providers and therefore limit strategic purchasing practices that depend on the bargaining power of the purchaser. Evidence from Indonesia, though not drawn from micro insurance, suggests that ensuring quality remains a challenge in settings where providers are limited in supply [60]. This finding is supported by work in Kenya which showed that purchasers were sometimes forced to accept providers' prices [35]. This evidence suggests that MHIs would face similar limitations even with an expressed intent to select appropriate providers. The main solution to this problem lies with the government, which stewards the health system. Several options exist including steps to train, attract and retain health workers in underserved areas [61]; and to discourage the over-supply of services in certain geographical areas [62]. MHIs could also influence the pattern of distribution by leveraging on member location to influence provider location and service type.

In terms of how to purchase, MHIs had a limited suite of incentives and sanctions over providers, which meant that they could not guarantee the quality or efficiency of services provided. This problem is observable in other purchasing mechanisms in Kenya and other LMIC [35, $52,63]$. For example, the use of contracts may be limited by the absence of a law or compulsion to contract certain types of providers. Diverse forms of provider payment mechanisms may also require appropriate regulation or financial management requirements. The application of sanctions may also be constrained by the need to maintain good relations with providers in the face of provider market power, as discussed above. More specifically, evidence 
from India suggests that MHIs have limited influence over providers especially where they continue to lie outside broader government initiatives to improve service availability and quality [64]. MHIs can take steps to ensure their suite of incentives and sanctions align with broader health system arrangements and goals. However, government can also undertake to provide frameworks for strategic purchasing that support system-wide approaches to introducing new provider payment mechanisms [65], other incentives and sanctions, and contractual relationships between purchasers and providers [66].

This study had several limitations. The case studies selected omitted the direct agent model which is also present in Kenya. This limitation is mitigated by the inclusion of Private Insurance Firm $\mathrm{C}$ which has experience in implementing the direct agent model. Also, while this paper does not report on the provider-driven model and the community-based models, commonly referred to as community-based health insurance in Kenya, the results of this examination are published elsewhere [35]. The other limitation is the inability to statistically generalize the findings to the rest of the country or other settings. The goal of qualitative analysis is to achieve analytical generalizability (i.e. generalizing to theory) rather than statistical generalisability. The study provides important insights into strategic purchasing practices of MHI that can be considered in the wide range of settings to which the concept of MHI is being applied.

\section{Conclusions}

MHI's potential role in purchasing health services for low-income earners in Kenya may not make a meaningful impact on the attainment of UHC goals because of the absence of strategic purchasing practices. Adequate policy, legal and regulatory frameworks are required that support strategic purchasing practice in Kenya. Specific to MHI, the frameworks should support the integration of MHIs into the broader health financing system in a way that would enhance progress towards UHC.

Development and implementation of these frameworks will require coordination across sectors. Specifically, state departments responsible for finance and health should form coordinating structures that ensure that MHI's role in UHC should be owned as an agenda across all relevant sectors, and that actors, such as regulators, perform in a coordinated manner.

This coordinated approach is particularly important in dealing with health service providers in order to optimise efficiency and quality health services. Specifically, the frameworks should seek to align provider selection, performance monitoring, incentives and sanctions, so that clear and consistent signals are received by providers from all purchasing mechanisms present within the health system.

\begin{abstract}
Abbreviations
$\mathrm{CBHI}$ : Community-based health insurance; IRA: Insurance Regulatory Authority; KES: Kenya Shillings; LMIC: Low- and middle-income countries; MHI: Micro Health Insurance; $\mathrm{MOH}$ : Ministry of Health; NHIF: National Hospital Insurance Fund; RESYST: Resilient and Responsive Health Systems; THE: Total Health Expenditure; UHC: Universal Health Coverage
\end{abstract}

\begin{abstract}
Acknowledgements
The authors thank all the study participants. This manuscript is published with the permission of the Director of KEMRI. This document is an output from a project funded by the UK Aid from the UK Department for International Development (DFID) for the benefit of developing countries. However, the views expressed and information contained in it are not necessarily those of or endorsed by DFID, which can accept no responsibility for such views or information or for any reliance placed on them. The funders and the World Bank had no role in study design, data analysis, decision to publish, drafting or submission of the manuscript. The views expressed in the papers are for the authors and not for the organizations they represent.
\end{abstract}

\section{Funding}

KM, SM, EB are members of the Consortium for Resilient and Responsive Health Systems (RESYST). Funds from the Wellcome Trust (\#101082) awarded to JC supported KM and SM. EB is funded by a Wellcome Trust Research Training Fellowship (\#107527). Additional funds from a Wellcome Trust core grant awarded to the KEMRI-Wellcome Trust Research Program (\#092654) supported this work. The funders and the World Bank had no role in study design, data analysis, decision to publish, drafting or submission of the manuscript.

\section{Availability of data and materials}

The transcripts generated and analysed during the current study are not publicly available as this may compromise the confidentiality of study participants. All relevant but deidentified data are included as quotes in the paper.

\section{Authors' contributions}

JC conceptualised the study; KM \& SM collected data, KM, SM, EB, JC analysed, and interpreted the data; KM developed the first draft; KM, SM, EB, $J C$ contributed to writing subsequent and final drafts. All the authors have given approval to the final manuscript to be published and agree to be accountable for the accuracy or integrity of any part of the work.

\section{Ethics approval and consent to participate}

The KEMRI Scientific and Ethics Review Unit approved this study under KEMRI SSC No.2795. All individual participants offered written informed consent.

Consent for publication

Not applicable.

\section{Competing interests}

The authors declare that they have no competing interests.

\section{Publisher's Note}

Springer Nature remains neutral with regard to jurisdictional claims in published maps and institutional affiliations.

\section{Author details}

${ }^{1}$ Institution: Health Economics Research Unit, KEMRI Wellcome Trust Research Programme, PO Box 43640 00100, Nairobi, Kenya. ${ }^{2}$ Nuffield Department of Medicine, Oxford University, Oxford, UK. ${ }^{3}$ The World Bank, Kenya Country Office, Nairobi, Kenya.

Received: 15 February 2018 Accepted: 28 December 2018

Published online: 18 January 2019

\section{References}

1. World Health Organization. The world health report: health systems financing: the path to universal coverage. Geneva: World Health Organization; 2010. 
2. Mclntyre D. Learning from experience: health care financing in low-and middle-income countries. Geneva: Global Forum for Health Research; 2007.

3. Smith PC, Witter SN. Risk Pooling in Health Care Financing : The Implications for Health System Performance. Health, Nutrition and Population (HNP) discussion paper; World Bank, Washington, DC. (c) World Bank. 2004. https://openknowledge.worldbank.org/handle/10986/13651. License: CC BY 3.0 IGO

4. Figueras J, Robinson R, Jakubowski E. Purchasing to improve health systems performance. In: Figueras J, McKee M, Mossialos E, Saltman RB, editors. European O. Berkshire: Open University Press; 2005.

5. Preker AS, Langenbrunner JC. Spending Wisely: Buying Health Service for the Poor. Washington DC: The World Bank; 2005.

6. Kutzin J. Anything goes on the path to universal health coverage? No Bull World Health Organ. 2012;90:867-8.

7. Kimball M, Phily C, Folsom A, Lagomarsino G, Holtz J, Internationa Labour Office. Leveraging health Microinsurance to Promote Universal Health Coverage [Internet]. Microinsurance Pap. Geneva: International Labour Office; 2013. Available from: http://www.impactinsurance.org/ publications/bn20.

8. Churchill CF, editor. Protecting the poor: a microinsurance compendium. Geneva: International Labour Organization; 2006.

9. Dror DM, Radermacher R, Khadilkar SB, Schout P, Hay FX, Singh A, et al. Microinsurance: innovations in low-cost health Insurance. Health Aff. 2009; 28:1788-98.

10. Wipf J, Garand D. Performance indicators for microinsurance: a handbook for microinsurance Practitioners. 2nd ed; Luxembourg: ADA asbl; 2010. Available from: https://microinsurancenetwork.org/sites/default/files/KPI_MI_ Handbook_v2_EN_0.pdf.

11. Dror DM, Piesse D. What is microinsurance? In: Radermacher R, Roth $\mathrm{K}$, editors. A Pract. Guid. to Impact Assessments Microinsurance. Luxembourg: Microinsurance Network and Micro Insurance Academy; 2014.

12. Holtz J, Hoffarth T, Phily C. Making Health Microinsurance Work. Geneva: Ten Recommendations for Practitioners; 2014. Report No.: 36.

13. Chuma J, Mulupi S, Mclntyre D. Providing financial protection and funding health service benefits for the informal sector. London: Evidence from subSaharan Africa; 2013. Report No.: 2.

14. Baeza C, Montenegro F, Nunez M. Extending social protection in health through community based health organizations: evidence and challenges. Geneva: International Labour Organization; 2002.

15. Carrin G, Waelkens MP, Criel B. Community-based health insurance in developing countries: a study of its contribution to the performance of health financing systems. Trop Med Int Heal. 2005;10:799-811.

16. Bennett S, Creese AL, Monasch R, Organization WH. Health insurance schemes for people outside formal sector employment. Geneva: World Health Organization; 1998.

17. Deglise C. Health microinsurance: a review of the Landscape \& Determinants of performance; 2016.

18. Health Sector Monitoring \& Evaluation Unit Ministry of Health Kenya. Status of Implementation of Free Maternity Services (FMS) Program in the Devolved Health System in Kenya. Nairobi: Ministry of Health [Kenya]; 2015.

19. Maina T, Kirigia D, Futures Group HPP. Annual evaluation of the abolition of user fees at primary healthcare facilities in Kenya. Washington DC: Health Policy Project; 2015.

20. National Hospital Insurance Fund. NHIF. Afya Yetu. Bima Yetu. [Internet]. National Hospital Insurance Fund; 2015. Available from: http://www.nhif.or. ke/healthinsurance/. Accessed 7 Jan 2019.

21. Republic of Kenya. Kenya: The Statute Law (Miscellaneous Amendments) Act 2014; 2014.

22. Githinji J. The Road to UHC in Kenya: Inside NHIF Reforms [Internet]. Joint Learning Network for Universal Health Coverage; 2016. Available from: http://www.jointlearningnetwork.org/news/the-road-to-universal-healthcoverage-in-kenya-a-peek-at-key-nhif-reforms-t . Accessed 7 Jan 2019.

23. Ministry of Health. Kenya household expenditure and utilisation survey 2013. Nairobi: Ministry of Health; 2014.

24. Matt Kukla, Josef Tayag, Agnes Gatome-Munyua, Abt Associates. What does the informal sector know about health insurance? Baseline findings from a knowledge, attitudes and perceptions survey in Nairobi, Kenya [internet]. Nairobi: SHOPS Strengthening Health Outcomes through the Private Sector; 2014. Available from: https://www. shopsplusproject.org/resource-center/what-does-informal-sector-knowabout-health-insurance. [Cited 2019 Jan 7].
25. FSD Kenya, Central Bank of Kenya. FinAccess National Survey 2013: Profiling developments in financial access and usage in Kenya. Nairobi: FinAccess; 2013.

26. Kenya National Bureau of Statistics. Statistical abstract 2016. Nairobi: Kenya National Bureau of Statistics; 2016.

27. Kenya National Bureau of Statistics. Economic survey 2016. Nairobi: Kenya National Bureau of Statistics; 2016.

28. Republic of Kenya. Sessional Paper No. 2 of 2014 on The National Social Protection Policy [Internet]. Nairobi Kenya; 2014. Available from: http://www socialprotection.or.ke/images/downloads/Draft-Sessional-Paper-SP-Jan2014. pdf. Accessed 7 Jan 2019.

29. Deloitte Consulting Limited. NHIF Strategic Review \& Market Assessment of Pre-paid Health Schemes: Measuring up. Strateg. Rev. NHIF-Final Rep. Nairobi: Deloitte Consulting Limited; 2011.

30. Government of Kenya. Sessional Paper No. 7 of 2012 on The Policy on Universal Health Care Coverage in Kenya [Internet]. Nairobi, Kenya: Ministry of Medical Services; 2012. Available from: http://publications. universalhealth2030.org/uploads/sessional_paper_no._7_-_universal_ coverage.pdf. [Cited 2019 Jan 7].

31. Insurance Regulatory Authority. The Kenya microinsurance policy paper. Nairobi: Insurance Regulatory Authority; 2014.

32. Dror DM, Soriano ES, Lorenzo ME, Sarol JN Jr, Azcuna RS, Koren R. Field based evidence of enhanced healthcare utilization among persons insured by micro health insurance units in Philippines. Health Policy (New. York). [Internet]. 2005/07/26. 2005;73:263-71. Available from: http://www. healthpolicyjrnl.com/article/S0168-8510(04)00266-0/abstract

33. Mulupi S, Kirigia D, Chuma J. Community perceptions of health insurance and their preferred design features: implications for the design of universal health coverage reforms in Kenya. BMC Health Serv Res. 2013;13.

34. Musau SN. Community-Based Health Insurance: Experiences and Lessons Learned from East Africa [Internet]. Bethesda MD; 1999. Report No.: 34. Available from: http://pdf.usaid.gov/pdf_docs/Pnach317.pdf . Accessed 7 Jan 2019.

35. Munge K, Mulupi S, Chuma J. A critical analysis of the purchasing arrangements in Kenya: the case of the National Hopsital Insurance Fund, Private and Community-based health insurance. London: RESYST; 2015.

36. Republic of Kenya. The Insurance Act. Kenya; 2014.

37. Mwaura JW, Pongpanich S. Access to health care: the role of a community based health insurance in Kenya. Pan Afr Med J. 2012;12:35.

38. Smith A, Chamberlain D, Smit H, Ncube S, Chelwa G. Kenya microinsurance landscape: market and regulatory analysis. Bellville: The Centre for Financial Regulation and Inclusion; 2010.

39. Koven R, Magnoni B, Zimmerman E, Sobol D, Budzyna L. Balancing client value and business case in Kenyan health microinsurance; 2014.

40. International Labour Organization. Extending Social Protection through Health Micro-Insurance Schemes to Women in the Informal Economy: Gender Strategy. Geneva: International Labour Organization; 2003.

41. Ministry of Health [Kenya]. Kenya Service Availability and Readiness Assessment Mapping (SARAM) Report. Nairobi: Ministry of Health Kenya; 2013.

42. Ministry of Health [Kenya]. Health Sector Strategic and Investment Plan II. Nairobi: Ministry of Health Kenya; 2012.

43. Ministry of Health [Kenya]. Kenya National Health Accounts 2012/13. Nairobi: Ministry of Health [Kenya]; 2015.

44. Insurance Regulatory Authority. Insurance industry report for the year ended 31st December 2013. Nairobi: Insurance Regulatory Authority; 2014.

45. Greyling, L. Literature Review of Health Microinsurance Systems. Johannesburg: Finmark Trust; 2014. Available from: http://www.finmark.org. za/wp-content/uploads/2016/01/Rep_Health-Case-studies_Final.pdf. [Cited 2019 Jan 7].

46. Impact Insurance, Changamka Micro-Insurance Limited, International Labour Office. Learning Journey Changamka Linda Jamii [Internet]. 2014. Available from: http://www.impactinsurance.org/sites/default/files/ 20141106\%20Changamka\%20Learning\%20Journey.pdf.

47. Business Call to Action. Advancing Bottom of the Pyramid ( BoP) Access to Healthcare: A Case Study on Mobile Money Platforms. Nairobi: Business Call to Action; 2016.

48. RESYST, Resilient and Responsive Health Systems. What is Strategic Purchasing for Health [Internet]. RESYST; 2014. Available from: https://resyst. Ishtm.ac.uk/resources/what-is-strategic-purchasing-for-health. Accessed 7 Jan 2019. 
49. Republic of Kenya. Microlnsurance Regulations 2015 (Draft) [Internet]. Kenya; 2015 p. 1-17. Available from: https://www.ira.go.ke/images/docs/Kenya_ Draft_Microinsurance_Regulations.pdf.

50. Ministry of Health [Kenya]. Kenya Health Policy 2014-2030: Towards attaining the highest standard of health. Nairobi, Kenya: Ministry of Health [Kenya]; 2014.

51. Medical Practitioners and Dentists Board. Fees guidelines for medical/ dental Practitioners. 3rd Editio. Medical Practitioners and Dentists Board: Nairobi; 2013.

52. Tran Thi Mai O, Hoang Thi P. Strategic Purchasing for Universal Health Coverage: A Critical Assessment Social Health Insurance Fund Vietnam [Internet]. London, UK: RESYST; 2016. Available from: https://resyst.Ishtm.ac. uk/resources/strategic-purchasing-for-universal-health-coverage-socialhealth-insurance-fund-in-vietnam.

53. Dash U. Is strategic purchasing feasible in publicly funded health systems with integrated purchasing and provision functions? A case study of Tamil Nadu, India. Int. Heal. Econ. World Congr. [Internet]. Milan: RESYST; 2015. Available from: https://www.slideshare.net/resyst/india-tax-fundedpurchasing-final.

54. Preker AS, Liu X, Velenyi EV, Baris E. Public Ends, Private Means: Strategic Purchasing of Health Services. Washington DC: The World Bank; 2007.

55. Tsofa B, Molyneux S, Goodman C. Health sector operational planning and budgeting processes in Kenya - "never the twain shall meet." Int J Health Plann Manage [lnternet] 2016;31:260-276. Available from: https://doi.org/10. 1002/hpm.2286.

56. Rasanathan K, Bennett S, Atkins V, Beschel R, Carrasquilla G, Charles J, et al. Governing multisectoral action for health in low- and middle-income countries. PLOS Med. [Internet]. Public Library of Science; 2017;14:e1002285. Available from: https://doi.org/10.1371/journal.pmed.1002285.

57. Shylendra H. S. Microfinance Institutions in Andhra Pradesh: Crisis and Diagnosis. Economic and Political Weekly, 2006;41(20):1959-963. Retrieved from http://www.jstor.org/stable/4418232.

58. Ashta A, Khan S, Otto P. Does Microfinance Cause or Reduce Suicides? Policy Recommendations for Reducing Borrower Stress. Strateg. Chang. [Internet]. 2015;24:165-90. Available from: https://doi.org/10.1002/jsc.2004. [cited 2017 May 16].

59. Institute for Health Metrics and Evaluation. GBD Compare [Internet]. 2016. Available from: https://vizhub.healthdata.org/gbd-compare/. [cited 2018 May 14].

60. Trisnantoro L, Hendrartini J, Susilowati T, Miranti PAD, Aristianti V. Chapter 3: A critical analysis of selected healthcare purchasing mechanisms in Indonesia. In: Honda A, Mcintyre D, Hanson K, Tangcharoensathien V, editors. Strateg. Purch. China, Indones. Philipp. Asia Pacific Observatory on Health Systems and Policies; London: RESYST; 2016. p. 96-139.

61. Njuguna J, Mwangi P, Kamau N. Incentives among Health Workers in a Remote Kenyan District: Implications for Proposed County Health System. J. Health Care Poor Underserved [Internet]. 2014;25:204-14. Available from: http://muse.jhu.edu/login?auth=0\&type=summary\&url=/journals/journal_of_ health_care_for_the_poor_and_underserved/v025/25.1.njuguna.html.

62. Liu X, Organization WH. Policy tools for allocative efficiency of health services. Geneva: World Health Organization; 2003.

63. Ogochukwu I. Is strategic purchasing a feasbile mechanism in the publicly funded health system of Nigeria? Int. Heal. Econ. Assoc. World Congr. [Internet]. Milan: RESYST; 2015. Available from: https://www.slideshare.net/ resyst/is-strategic-purchasing-a-feasible-mechanism-in-the-publicly-fundedhealth-system-of-nigeria.

64. Michielsen J, Criel B, Devadasan N, Soors W, Wouters E, Meulemans H. Can health insurance improve access to quality care for the Indian poor? Int J Qual Heal Care [Internet] 2011;23:471-486. Available from: https://doi.org/10, 1093/intahc/mzr025

65. Agyepong IA, Aryeetey GC, Nonvignon J, et al. Advancing the application of systems thinking in health: provider payment and service supply behaviour and incentives in the Ghana National Health Insurance Scheme--a systems approach. Health Res Policy Syst. 2014;12:35. Published 2014 Aug 5. https:// doi.org/10.1186/1478-4505-12-35.

66. Ssengooba F, McPake B, Palmer N. Why performance-based contracting failed in Uganda - an "open-box" evaluation of a complex health system intervention. Soc Sci Med. 2012;75:377-83.

\section{Ready to submit your research? Choose BMC and benefit from:}

- fast, convenient online submission

- thorough peer review by experienced researchers in your field

- rapid publication on acceptance

- support for research data, including large and complex data types

- gold Open Access which fosters wider collaboration and increased citations

- maximum visibility for your research: over $100 \mathrm{M}$ website views per year

At BMC, research is always in progress.

Learn more biomedcentral.com/submissions 